\title{
Caracterização físico-química de polpas de manga 'Rosa' liofilizadas
}

\section{Physical-chemical characterization of freeze-dried mango 'Rosa' pulps}

\author{
Marcela Nobre Oliveira ${ }^{1}$; Rossana Maria Feitosa de Figueirêdo ${ }^{2}$; Alexandre José de Melo Queiroz ${ }^{3}$; Adelino de Melo \\ Guimarães Diógenes ${ }^{4}$; Alison Bruno Borges de Sousa ${ }^{5}$; Ubieli Alves Araújo Vasconcelos ${ }^{6}$
}

\begin{abstract}
Resumo: Objetivou-se neste estudo realizar a caracterização físico-química de polpa de manga 'Rosa' em pó, obtida por liofilização. Utilizou-se polpa integral e uma formulação contendo $30 \%$ de maltodextrina (agente de secagem). As amostras foram homogeneizadas e congeladas a $-18^{\circ} \mathrm{C}$ para posterior liofilização por um período de 72 horas. Realizou-se análises das polpas (integral e formulada) e dos pós obtidos quanto aos parâmetros de umidade, atividade de água, sólidos solúveis totais, $\mathrm{pH}$, acidez total titulável, ácido ascórbico e cor instrumental. Verificou-se que a adição do agente carreador alterou as características da polpa com diminuição da umidade, atividade de água, acidez total titulável e ácido ascórbico, elevando o teor de sólidos solúveis totais. Na polpa formulada observou-se aumento de $34 \%$ dos sólidos solúveis totais, enquanto que a redução da atividade de água foi de quase $80 \%$. Em relação ao pó, o produto com maltodextrina apresentou redução nos teores de umidade, atividade de água e acidez total titulável quando comparado ao pó de fruta integral. Quanto à cor, houve aumento da luminosidade $\left(\mathrm{L}^{*}\right)$, de 72,45 para 78,85 e decréscimo da intensidade de amarelo $\left(+\mathrm{b}^{*}\right)$, de 62,72 para 35,33 , do pó formulado quando comparado ao pó sem adição de adjuvante. Foi possível verificar que a inclusão de maltodextrina alterou os parâmetros físico-químicos estudados, tanto nas polpas quanto no pó liofilizado, sendo os parâmetros de umidade, atividade de água e luminosidade os mais afetados.
\end{abstract}

Palavras-chave: Mangifera indica L.; Secagem; Desidratação; Maltodextrina.

Abstract: The objective of this study was to perform the physico-chemical characterization of 'Rosa powder' mango pulp obtained by lyophilization. Integral pulp and a formulation containing 30\% maltodextrin (drying agent) were used. Samples were homogenized and frozen at $-18^{\circ} \mathrm{C}$ for further lyophilization for a period of 72 hours. Analyzes of the pulps (integral and formulated) and the post-obtained were performed for unit parameter, water activity, total soluble solids, $\mathrm{pH}$, total titratable acidity, ascorbic acid and instrumental color. It was verified that the addition of the road agent altered as characteristics of the pulp with decrease of the moisture content, water activity, titratable total acid and ascorbic acid, increasing the total soluble solids content. In the formulated pulp a $34 \%$ increase of the total soluble solids was observed, whereas the reduction of the water activity was almost $80 \%$. In relation to the powder, the maltodextrin product presented a reduction in moisture contents, water activity and titratable total acidity when compared to whole fruit powder. As for color, there was an increase in luminosity $(\mathrm{L} *)$, from 72.45 to 78.85 and a decrease in the intensity of yellow $(+\mathrm{b} *)$, from 62.72 to 35.33 , of the formulated powder when compared to the powder without addition of adjuvant. It was possible to verify that the inclusion of maltodextrin altered the physical-chemical parameters studied, both in the pulps and lyophilized powder, being the parameter of a unit, water activity and luminosity of the most affected.

Keywords: Mangifera indica L.; Drying; Dehydration; Maltodextrin.

\footnotetext{
*Autor para correspondência

Recebido para publicação em 01/03/2017; aprovado em 05/06/2017

${ }^{1}$ Doutoranda em Engenharia agrícola, Universidade Federal de Campina Grande, Campina Grande, Paraíba, marcela_nobre@msn.com.;

${ }^{2}$ Professora Titular, Universidade Federal de Campina Grande, Campina Grande, Paraíba, rossanamff@ gmail.com;

${ }^{3}$ Professor Titular, Universidade Federal de Campina Grande, Campina Grande, Paraíba, alexandrejmq@ gmail.com;

${ }^{4}$ Professor de Agroindústria, Instituto Federal de Educação, Ciência e Tecnologia de Pernambuco, Afogados da Ingazeira, Pernambuco, adelinoguimaraes@hotmail.com;

${ }^{5}$ Professor de Agroindústria, Instituto Federal de Educação, Ciência e Tecnologia de Pernambuco, Afogados da Ingazeira, Pernambuco, alisonbruno.alimentos@gmail.com; ${ }^{6}$ Doutorando em Fitotecnia, Universidade Federal de Viçosa, Viçosa, Minas Gerais, ubieli_araujo@hotmail.com.
} 


\section{INTRODUÇÃO}

A manga (Mangifera indica L.) é uma fruta tropical carnosa, de tamanho e forma variáveis, rica em sais minerais, vitaminas, açúcares, carotenoides, compostos fenólicos e ácido ascórbico (MELO; ARAÚJO, 2011).

Devido ao seu sabor, aroma e valor nutricional, a manga 'Rosa' é bastante utilizada na culinária brasileira (BEZERRA et al., 2011). Sua comercialização está concentrada na forma de fruto in natura, porém produtos industrializados vêm despertando o interesse dos consumidores (BENEVIDES et al., 2008).

Uma técnica de conservação de derivados de frutas com o consequente aumento da vida útil é a liofilização. Este processo transforma a polpa da fruta em um pó através da remoção da água por sublimação (ZOTARELLI, 2014). Nesse caso, a água não passa pelo estado líquido e a dinâmica entre vácuo e baixa temperatura promove a sublimação. Dessa forma, as propriedades químicas e organolépticas teoricamente pouco se alteram e o procedimento pode ser aplicado a produtos sensíveis ao calor. Além disso, o produto liofilizado é facilmente reidratável, pois poros microscópicos são formados como resultado dos cristais de gelo que sublimam durante o processo de secagem (OIKONOMOPOULOU et al., 2011).

Produtos alimentícios em pó se caracterizam por possuírem um alto teor de sólidos solúveis, com uma porção apreciável destes no estado amorfo (vítreo), que os torna altamente higroscópicos e sujeitos a mudanças físicas indesejáveis (CARLOS et al., 2005; SOARES et al., 2001). Para combater estas mudanças, pode-se adicionar às matériasprimas um agente carreador, como as maltodextrinas, que possuem alta solubilidade e baixa higroscopicidade (AZEREDO, 2005; GHARSALLAOUI et al., 2007). O uso de adjuvantes de secagem como as maltodextrina pode influenciar as características, físicas, físico-químicas e químicas dos alimentos.

Estudos têm mostrado alterações nos parâmetros físicoquímico relacionados a aplicação do método de secagem por liofilização em diversas frutas, tais como abacaxi, manga, mamão, papaya e acerola (MARQUES, 2008); acerola (NÓBREGA, 2012); graviola (CEBALLOS et al. 2012); araçá e grajubú (NORA, 2012).

Diante do exposto, o presente trabalho teve como objetivo caracterizar por meio de parâmetros físico-químicos a polpa de manga 'Rosa' integral, a polpa formulada (polpa de manga com $30 \%$ de maltodextrina) e os pós obtidos a partir da liofilização da polpa integral e da polpa formulada.

\section{MATERIAL E MÉTODOS}

As mangas (Mangifera indica L.) da variedade 'Rosa' foram adquiridas no comércio varejista da cidade de Campina Grande, Paraíba, e transportadas para o Laboratório de Armazenamento e Processamento de Produtos Agrícolas da Universidade Federal de Campina Grande. No laboratório, os frutos foram lavados, higienizados, descascados e despolpados para obtenção da polpa integral.

Obteve-se duas formulações de polpa para posterior liofilização. A polpa integral, sem adição de nenhum aditivo, denominada "Tipo A", e a polpa adicionada de $30 \%$ de maltodextrina com dextrose equivalente igual a $10(\mathrm{DE}=10)$, descrita como "Tipo B".

As polpas integral e formulada foram homogeneizadas, colocadas em bandejas apropriadas e posteriormente congeladas em freezer a $-18{ }^{\circ} \mathrm{C}$ por 24 horas. Em seguida, foram desidratadas em liofilizador a temperatura de $-50 \pm 2{ }^{\circ} \mathrm{C}$ por 72 horas.

As amostras liofilizadas foram trituradas em almofariz com pistilo até constituírem um pó. Padronizou-se os pós obtidos com a mesma denominação utilizada anteriormente para as polpas, sendo o pó integral identificado por pó "Tipo A" e o pó liofilizado com maltodextrina, descrito como "Tipo B".

As análises físico-químicas foram realizadas nas polpas integral, formulada e nos pós "tipo A" e "tipo B", de acordo com as metodologias do Instituto Adolfo Lutz (2008) para pH (método potenciométrico), sólidos solúveis totais (método refratométrico) e umidade. Seguindo as metodologias descritas pela AOAC (2000), foram determinadas acidez total titulável (\% ácido cítrico) e ácido ascórbico (modificada por BENASSI; ANTUNES, 1998). Também foram realizadas análises para atividade de água a $25{ }^{\circ} \mathrm{C}$, medida direta em medidor Aqualab, modelo 3TE da Decagon devices.

A cor das amostras foi determinada por meio dos parâmetros $\mathrm{L}^{*}, \mathrm{a}^{*}$ e $\mathrm{b}^{*}$ medidos com o espectrofotômetro portátil Hunter Lab Mini Scan XE Plus, modelo 4500 L, em que $\mathrm{L}^{*}$ define a luminosidade $\left(\mathrm{L}^{*}=0-\right.$ preto e $\mathrm{L}^{*}=100-$ branco) e $a^{*}$ e $b^{*}$ são coordenadas de cromaticidade $\left(+a^{*}\right.$ vermelho e $-a^{*}$ verde; $+b^{*}$ amarelo $\mathrm{e}-\mathrm{b}^{*}$ azul). Todas as análises foram realizadas em triplicata.

Aplicou-se o Delineamento Inteiramente Casualizado, sendo duas formulações de polpa e duas formulações de pó liofilizado, com três repetições. Os dados experimentais obtidos na caracterização físico-química da polpa de manga integral e formulada foram tratados estatisticamente através de análise de variância (ANOVA) com uso do programa Assistat, versão 7.7 Beta (SILVA; AZEVEDO, 2009). A comparação entre médias foi realizada por meio do teste de Tukey a 5\% de probabilidade.

\section{RESULTADOS E DISCUSSÃO}

Na Tabela 1, oberva-se os valores da caracterização físico-química das polpas de manga 'Rosa' integral e formulada. Na umidade observa-se diferença estatisticamente significativa entre as amostras, efeito da adição de sólidos representados pela maltodextrina. A umidade da polpa de manga "integral" foi próxima ao percentual determinado por Breda et al. (2013) quando reportaram um valor de 82,71\% em polpa integral de cajamanga. Diógenes et al. (2015b), também verificaram que a adição de maltodextrina à polpa integral de manga 'Haden' reduziu o teor de água devido ao aumento dos sólidos na formulação.

$\mathrm{O}$ parâmetro atividade de água das polpas integral e formulada não diferiram estatisticamente ( $p>0,01)$, de acordo com os dados obtidos, apesar do valor absoluto menor na polpa formulada. Diferença menor, porém estatisticamente significativa, foi observada por Feitosa (2014), que encontrou valores de atividade de água diferentes para as polpas integral e formulada de murta, com valores de 0,983 e 0,989, respectivamente. 
Tabela 1. Valores médios e desvios padrão dos parâmetros físico-químicos das polpas de manga 'Rosa'

\begin{tabular}{lcc}
\hline \multicolumn{1}{c}{ Parâmetro } & Integral & Formulada \\
\hline Umidade (\%) & $83,54 \pm 0,05 \mathrm{a}$ & $66,54 \pm 0,34 \mathrm{~b}$ \\
Atividade de água & $0,982 \pm 0,001 \mathrm{a}$ & $0,974 \pm 0,001 \mathrm{a}$ \\
Sólidos solúveis totais ( ${ }^{\circ}$ Brix) & $15,0 \mathrm{~b}$ & $34,0 \mathrm{a}$ \\
$\mathrm{pH}$ & $4,28 \pm 0,08 \mathrm{a}$ & $4,34 \pm 0,04 \mathrm{a}$ \\
Acidez total titulável (\% ac. cítrico) & $8,90 \pm 0,33 \mathrm{a}$ & $4,35 \pm 0,29 \mathrm{~b}$ \\
Ácido ascórbico (mg/100 g) & $0,40 \pm 0,01 \mathrm{a}$ & $0,33 \pm 0,01 \mathrm{~b}$ \\
Luminosidade (L*) & $55,05 \pm 0,01 \mathrm{a}$ & $49,79 \pm 0,25 \mathrm{~b}$ \\
Intensidade de vermelho (+a*) & $11,13 \pm 0,02 \mathrm{a}$ & $10,64 \pm 0,16 \mathrm{~b}$ \\
Intensidade de amarelo (+b*) & $61,90 \pm 0,08 \mathrm{a}$ & $57,37 \pm 0,21 \mathrm{~b}$ \\
\hline
\end{tabular}

Médias seguidas da mesma letra nas linhas não diferem estatisticamente pelo teste de Tukey, a $1 \%$ de probabilidade.

A polpa de manga integral apresentou sólidos solúveis totais (SST) de $15^{\circ}$ Brix, valor intermediário ao encontrado por Duarte et al. (2006) e Mújica-Paz et al. (2003) em manga 'Tommy Atkins', de 14,0 e 16,1 'Brix, respectivamente. A adição de maltodextrina acarretou um aumento do SST de mais de $100 \%$ na polpa formulada em relação à polpa integral.

Em relação a acidez total titulável (ATT) observou-se teor de cerca de $9 \%$ na amostra integral, valor que se reduz em mais de $50 \%$ na polpa formulada como resultado da adição de maltodextrina. $O$ acréscimo de aditivos tende a reduzir a ATT e aumentar o pH, e é isso que se observa, com um $\mathrm{pH}$ ligeiramente maior na amostra formulada. Chitarra e Chitarra (2005) reportaram que a maltodextrina reduz nas polpas de frutas a concentração dos ácidos orgânicos presentes, aumentando o $\mathrm{pH}$. O mesmo comportamento do $\mathrm{pH}$ foi observado por Melo (2012) ao comparar polpas de atemoia integral e formulada.

Quanto aos teores de ácido ascórbico das polpas, verificou-se uma redução destes valores ao se adicionar maltodextrina, apresentando diferença estatisticamente significativa $(p<0,01)$. Valores bem superiores foram encontrados por Silva Filho et al. (2012) em polpa de manga 'Espada' (8,43 $\pm 0,208 \%$ de ácido cítrico). Esse fato pode ser explicado pelos fatores que influenciam o teor de ácido ascórbico, tais como: variedade e estádio de maturação do fruto, condições e tempo de armazenamento da polpa (CHITARRA; CHITARRA, 2005).

$\mathrm{Na}$ análise de cor, constatou-se que os maiores valores de $L^{*}, a^{*}, b^{*}$ foram obtidos na polpa "integral", indicando certo escurecimento e reduções nos matizes vermelho e amarelo da polpa formulada em relação à polpa integral. Benevides et al. (2008) relataram resultados semelhantes para a cor da polpa in natura de manga 'Ubá', reportando aparência clara, com predominância do matiz amarelo sobre o vermelho, resultando na cor amarelo-alaranjada, característica do produto analisado. Embora a associação dos três parâmetros seja importante na avaliação da cor de um produto, para o produto estudado (manga) o parâmetro b* é um dos mais relevantes a ser utilizado para distinção das diferenças de cor resultantes dos processos de secagem desse produto (CAPARINO et al., 2012).

$\mathrm{Na}$ Tabela 2 verifica-se os valores médios e desvios padrão dos parâmetros físico-químicos da polpa de manga 'Rosa' em pó “Tipo A" e "Tipo B". A umidade dos pós diferiu estatisticamente entre si $(p \leq 0,01)$, onde a amostra contendo maltodextrina apresentou uma redução no teor de umidade de cerca de 1/3 em relação à amostra "Tipo A". Acompanhando este comportamento, a atividade de água da amostra "Tipo B" demonstrou uma redução de mais de $36 \%$ em relação à amostra tipo A. A umidade manteve o mesmo comportamento atribuído a atividade de água na relação polpa

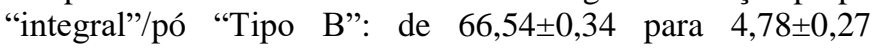
(redução de 93\%). Zotarelli (2014) e Moreira et al. (2013), ambos analisando a umidade de polpa de manga 'Tommy Atkins', observaram diminuição dos valores deste parâmetro ao liofilizarem a polpa obtendo pó na ordem de 96,90\% e $96,32 \%$, respectivamente. Pedro et al. (2010), observaram valores de atividade de água em torno de 0,206 em seus estudos com pós de polpa de maracujá adicionados de $55 \%$ de maltodextrina, obtidos por liofilização; este valor está muito próximo dos encontrados neste estudo. De acordo com Benedetti et al. (2011), a adição de maltodextrina evitou a pegajosidade e aglomeração do pó de caqui durante o processamento e o armazenamento.

Tabela 2. Valores médios e desvios padrão dos parâmetros físico-químicos da polpa de manga 'Rosa' em pó liofilizada

\begin{tabular}{lcc}
\hline \multicolumn{1}{c}{ Parâmetro } & Tipo A & Manga em pó \\
\cline { 2 - 3 } & $13,75 \pm 0,65 \mathrm{a}$ & Tipo B \\
\hline Umidade (\%) & $0,346 \pm 0,001 \mathrm{a}$ & $4,78 \pm 0,27 \mathrm{~b}$ \\
Atividade de água & $4,21 \pm 0,058 \mathrm{a}$ & $0,219 \pm 0,011 \mathrm{~b}$ \\
pH & $1,46 \pm 0,04 \mathrm{a}$ & $4,18 \pm 0,058 \mathrm{a}$ \\
Acidez total titulável (\% ac. cítrico) & $16,82 \pm 0,45 \mathrm{a}$ & $0,68 \pm 0,04 \mathrm{~b}$ \\
Ácido ascórbico (mg/100 g) & $72,45 \pm 0,03 \mathrm{~b}$ & $15,00 \pm 0,076 \mathrm{~b}$ \\
Luminosidade (L*) & $10,86 \pm 0,05 \mathrm{a}$ & $78,85 \pm 0,14 \mathrm{a}$ \\
Intensidade de vermelho (+a*) & $62,72 \pm 0,21 \mathrm{a}$ & $2,79 \pm 0,03 \mathrm{~b}$ \\
Intensidade de amarelo (+b*) & $35,33 \pm 0,21 \mathrm{~b}$ \\
\hline
\end{tabular}

As médias seguidas da mesma letra nas linhas não diferem estatisticamente pelo teste de Tukey, a nível de 5\% de probabilidade.

Estudo realizado por Mosquera et al. (2012), reportaram melhora na estabilidade do morango em pó adicionado de maltodextrina, a qual auxiliou na diminuição da atividade de água. Comparando os valores do pó "tipo B" com a polpa integral nota-se que a redução da atividade de água do pó "tipo B" foi de quase $80 \%$ em relação à polpa "integral". 
Almeida et al. (2009), analisando a atividade de água do pó de manga 'Rosa' liofilizado, adicionado de agente carreador, observaram uma redução em torno de $90 \%$ em relação a polpa integral.

Cano-Higuita et al. (2013) avaliaram a influência da maltodextrina, do leite desnatado (skimmedmilk) e a mistura desses compostos nas isotermas de sorção de manga em pó. Os autores constataram que a formulação de 1:8 de polpa de manga/maltodextrina foi a combinação que menos adsorveu umidade, devido à maior quantidade de sólidos de baixa higroscopicidade presentes.

A quantidade de sólidos totais na polpa de manga 'Rosa' ficou em torno de 15\%; ao se acrescentar $30 \%$ de maltodextrina à polpa, a quantidade deste agente aumentou para cerca de $34 \%$; nas amostras de pó "Tipo B" foi de cerca de $13 \%$.

A acidez total titulável do pó de manga tipo "A" foi reduzida em mais de $53 \%$ com a adição de maltodextrina. Semelhante redução, mas em escala muito superior observada por Diógenes et al. (2015a), com diminuição de mais de $240 \%$ da acidez total titulável em pó liofilizado de manga 'Haden'.

Valores superiores de ácido ascórbico ao deste trabalho foram encontrados por Bezerra et al. (2011) em polpas de manga 'Rosa' e 'Tommy Atkins', respectivamente de 52,11 e $36,24 \mathrm{mg} / 100 \mathrm{~g}$. A alta concentração de ácido ascórbico no pó, em comparação com as amostras antes da secagem pode ser explicada em razão da concentração deste princípio em razão da redução da umidade na secagem e da baixa degradação da matéria-prima que é característica do processo de liofilização (SAGA; SURESH, 2010).

A adição de maltodextrina à polpa também influenciou os valores da análise colorimétrica; a luminosidade $\left(\mathrm{L}^{*}\right)$ do pó adicionado de maltodextrina apresentou maior valor devido à coloração praticamente branca da maltodextrina. Para as coordenadas $a^{*}$ e $b^{*}$, observou-se uma diminuição nesses parâmetros no pó “tipo B". Segundo Tonon et al. (2009), esta redução da tonalidade do vermelho e amarelo pode estar relacionada à diluição da cor, provocada pela presença do agente carreador utilizado.

\section{CONCLUSÕES}

A polpa "formulada" apresenta menores valores de umidade, acidez total titulável, pH e ácido ascórbico, devido à incorporação de maltodextrina. A maltodextrina também influencia no aumento do teor de sólidos solúveis totais da polpa formulada em relação à polpa integral.

O pó "tipo B" de origem da polpa formulada apresenta interferência da maltodextrina diminuindo os teores de umidade e atividade de água, da acidez total titulável e aumentando os teores de SST, em relação ao pó sem maltodextrina. A adição de maltodextrina à polpa aumenta a luminosidade $\left(\mathrm{L}^{*}\right)$ e reduz a intensidade de vermelho e de amarelo do pó.

\section{REFERÊNCIAS}

ALMEIDA, P.; MEIRA, T.; ALENCAR, L. C.; FREITAS, A.; HERCULANO, L. Avaliação físico-química de pósalimentícios de manga (Mangifera indica L.) de diferentes variedades obtidas pelo processo de liofilização. Encontro
Nacional do Programa de Pós-graduação. Anais... Fortaleza, Ceará, 2009.

AOAC, ASSOCIATION OF OFFICIAL ANALYTICAL CHENISTS. HORWITZ, W. (Ed) Official Methods of Analysis of Association of Official Analytical Chemists. 17 ed. Arlington: AOAC Inc., 2000. v1 e v2.

AZEREDO, H. M. C. de. Encapsulação: aplicação à tecnologia de alimentos. Alimentos e Nutrição, Araraquara, v. 16, n. 1, p. 89-97, 2005. ISSN: 0103-4235.

BENASSI, M. T.; ANTUNES, A. J. A. Comparison of metaphosphoric and oxalic acids as extractant solutions for the determination of vitamin $\mathrm{C}$ in selected vegetables. Arquivos de Biologia e Tecnologia, Curitiba, v. 31, n. 4, p. 507-513, 1998. ISSN: 1678-4324.

BENEDETTI, P. de C. D.; PEDRO, M. A. M.; TELISROMERO, J.; TELIS, V. R. N. Influence of encapsulating materials on water sorption isotherms of vacuum-dried persimmon pulp powerd. Journal of Food Processing and Preservation, Pullman, n. 35, p. 423-431, 2011. INSS: 17454549.

BENEVIDES, S. D.; RAMOS, A. M.; STRINGHETA, P. C.; CASTRO, V. C. Qualidade da manga e polpa da manga Ubá. Revista Ciência e Tecnologia de Alimentos, Campinas, v. 28, n. 3, p. 571-578, 2008. ISSN: 1678-457X.

BEZERRA, T. S.; COSTA, J. M. C. da; AFONSO, M. R. A; MAIA, G. A.; CLEMENTE, E. Avaliação físico-química e aplicação de modelos matemáticos na predição do comportamento de polpas de manga desidratadas em pó. Revista Ceres, Viçosa, v. 58, n.3, p. 278-283, 2011. ISSN: 2177-3491.

BREDA, C. A.; JUSTI, P. N.; SANJINEZ-ARGANDOÑA, E. J. Efeito da desidratação foammat na retenção da vitamina C da polpa de cajamanga. Alimentos e Nutrição Brazilian Journal Foods Nutrition, Araraquara, v. 24, n. 2, p. 189193,2013. ISSN: 2179-4448.

CANO-HIGUITA, D. M.; VILLA-VELEZ, H. A.; TELISROMERO, J.; VAQUIRO, H. A.; TELIS, V. R. N. Influence of alternative drying aids on water sorption of spray dried mango mix powders: a thermodynamic approach. Food and Bioproducts Processing, Rugby, v. 93, p. 19-28, 2013. ISSN: 0960-3085.

CAPARINO, O. A.; TANG, J.; NINDO, C. I.; SABLANI, S. S.; POWERS, J. R.; FELLMAN, J. K. Effect of drying methods on the physical properties and microstructures of mango (Philippine 'Carabao' var.) powder. Journal of Food Engineering, London, v. 111, n. 1, p. 135-148, 2012. ISSN: 0260-8774.

CARLOS, L. A.; RESENDE, J. V.; CAL-VIDAL, J. Redução da higroscopicidade de pós liofilizados pela indução da cristalização em soluções-modelo de açúcares constituintes de frutas. Brazilian Journal of Food Technology, Campinas, n. 8, p. 163-173, 2005. ISSN: 1519-0900.

CEBAllos, A. M.; GIRAlDO, G. I.; ORREGO, C. E. Effect of freezing rate on quality parameters of freeze dried soursop fruit pulp. Journal of Food Engineering, London, v.111, n.2, p.360-365, 2012. 
CHITARRA, M. I. F.; CHITARRA, A. B. Pós-colheita de frutos e hortaliças: fisiologia e manuseio. 2. ed. rev. e ampl. Lavras: UFLA, 2005. 783 p.

DIÓGENES, A. de M. G.; FIGUEIRÊDO, R. M. F.; QUEIROZ, A. J. de MELO. Análise comparativa de pós obtidos por liofilização de polpas de manga 'Haden'. In: XIX Encontro Nacional e V Congresso Latino Americano de Analistas de Alimentos: Desafios Analíticos e Segurança Alimentar, 2015, Anais... Natal, 16-20 de Agosto, 2015 (a).

DIÓGENES, A. de M. G.; FIGUEIRÊDO, R. M. F.; SOUSA, A. B. B. de. Análise comparativa de polpas de manga 'Haden' integral e formulada, Revista AGROTEC, Areia, v. 36, n. 1, p. 30-34, 2015 (b). ISSN: 2179-5959.

DUARTE, M. E. M.; MATA, M. E. R. M.; AGRA, N. G. Comparação entre as características físico-químicas da manga liofilizada e a manga-passa. Revista Brasileira de Produtos Agroindustriais, Campina Grande, v.8, n.2, p.127-134, 2006. ISSN: $1807-1929$.

FEITOSA, R. M. Secagem por aspersão e em camada de espuma da polpa de murta. 2014. 236 f. 2012. 230 f. Tese (Doutorado em Eng. Agrícola) - Universidade Federal de Campina Grande, Centro de Tecnologia e Recursos Naturais, Campina Grande, PB.

GHARSALLAOUI, A.; ROUDART. G.; CHAMBIN, O.; VOILLEY, A.; SAUREL, R. Applications of spray drying in microencapsulation of food ingredients: an overview. Food Research International, Amsterdam, v. 40, n. 9, p. 1107-1121, 2007. ISSN: 0963-9969.

INSTITUTO ADOLFO LUTZ. Métodos físico-químicos para análise de alimentos. 5 ed. São Paulo, 2008. 1032 p.

MARQUES, L. G. Liofilização de frutas tropicais. 2008. 255p. Tese (Doutorado em Engenharia Química) - Centro de Ciências Exatas e de Tecnologia, Programa de Pós-Graduação em Engenharia Química, Universidade Federal de São Carlos. São Carlos, 2008.

MELO, E. de A.; ARAÚJO, C. R. de. Mangas das variedades espada, rosa e Tommy atkins: compostos bioativos e potencial antioxidante. Semina: Ciências Agrárias, Londrina, v. 32 , n. 4, p. 1451-1460, 2011. ISSN: 1679-0359.

MELO, K. dos S. Secagem por aspersão de polpa de atemóia. 2012. 230 f. Tese (Doutorado em Eng. Agrícola) Universidade Federal de Campina Grande, Centro de Tecnologia e Recursos Naturais, Campina Grande, 2012.

MOREIRA, T. B.; ROCHA, E. M. F. F.; AFONSO, M. R. A.; COSTA, J. M. C. Comportamento das isotermas de adsorção do pó da polpa de manga liofilizada. Revista Brasileira de Engenharia Agrícola e Ambiental, Campina Grande, v.17, n.10, p. 1093-1098, 2013. ISSN: 1807-1929.

MOSQUERA, L. H.; MORAGA, G.; MARTÍNEZNAVARRETE, N. Critical water activity and critical water content of freeze-dried strawberry powder as affected by maltodextrin and arabic gum. Food Research International, Burlongton, v. 47, n. 2, p. 201-206, 2012. ISSN: 0963-9969.

MÚJICA-PAZ, H. VALDEZ-FRAGOSO, A.; LÓPEZMALO, A.; PALOU, E.; WELTICHANES, J. Impregnation and osmotic dehydration of some fruits: effects of the vacuum pressure and syrup concentration. Journal of Food
Engineering, London, v. 57, n.4, p.305-314, 2003. ISSN: 0260-8774.

NÓBREGA, E. M. M. de A. Secagem do resíduo de acerola (Malphigia emarginata DC.): estudo do processo e avaliação do impacto sobre o produto final. 2012. 102p. Dissertação (Mestrado em Engenharia Química) - Centro de Tecnologia, Departamento de Engenharia Química, Programa de PósGraduação em Engenharia Química, Universidade Federal do Rio Grande do Norte. Natal, 2012.

NORA, C. D. Caracterização, atividade antioxidante "in vivo" e efeito do processamento na estabilidade de compostos bioativos de araçá vermelho e guajibu. 2012.91p. Dissertação (Mestrado em Ciência e Tecnologia de Alimentos). Faculdade de Ciência e Tecnologia de Alimentos, Programa de PósGraduação em Ciência e Tecnologia de Alimentos, Universidade Federal do Rio Grande do Sul. Porto Alegre, 2012.

OLIVEIRA, G. S. Aplicação do processo de liofilização na obtenção de cajá em pó: avaliação das características físicas, físico-químicas e higroscópicas. 2012. 83p. Dissertação (Mestrado em Ciência e Tecnologia de Alimentos). Centro de Ciências Agrárias Departamento de Tecnologia de Alimentos, Programa de Pós-Graduação em Ciências e Tecnologia de Alimentos, Universidade Federal do Ceará. Fortaleza, 2012.

PEDRO, M. A. M.; TELIS-ROMERO, J.; TELIS, V. R. N. Effect of drying method on the adsorption isotherms and isosteric heat of passion fruit pulp powder. Ciência e Tecnologia de Alimentos, Campinas, v. 30, n. 4, p. 993-1000, 2010. ISSN: 0101-2061.

SAGAR, V. R.; SURESH, K. P. Recent advances in drying and dehydration of fruits and vegetables: a review. Journal of Food Science and Technology, Mysuru, v.47, n.1, p.15-26, 2010. ISSN: 0260-8774.

SILVA FILHO, E. D. da; OLIVEIRA, A. G. Cabral de; MADUREIRA, I. A.; FAUSTINO, S. N. de. Estudo das análises químicas e físico-químicas da polpa da manga cv. Espada. In: VII CONEPI. Anais... Palma, TO, de 18 a 21 de agosto, 2012

SILVA, F. A. S, AZEVEDO, C. A. V. Principal components analysis in the software assistat-statistical attendance. In: World Congress on Computers in Agriculture, 7, Reno-NVUSA: American Society of Agricultural and Biological Engineers, 2009.

SOARES, E. C.; OLIVEIRA, G. S. F.; MAIA, G. A.; MONTEIRO, J. C. S.; SILVA JÚNIOR, A. S.; FILHO, M. S. S. Desidratação da polpa de acerola (Malpighiaemarginata $D$. C.) pelo processo "foam-mat". Ciência e Tecnologia de Alimentos, Campinas, v.21, p. 164-170, 2001. ISSN: 1678$457 \mathrm{X}$.

TONON, R. V.; BRABET, C.; HUBINGER, M. D. Influência da temperatura do ar de secagem e da concentração de agente carreador sobre as propriedades físico-químicas do suco de açaí em pó. Ciência e Tecnologia de Alimentos, Campinas, v.29, n.2, p.444-450, 2009. ISSN: 1678-457X.

ZOTARELlI, M. F. Produção e Caracterização de Manga Desidratada em Pó por Diferentes Processos de Secagem. 2014. 165 p. Tese (Doutorado) - Universidade Federal de Santa Catarina, Centro Tecnológico. Programa de PósGraduação em Engenharia Química. Florianópolis, SC. 